\title{
The Relationship between Humans and Other Animals in European Animal Welfare Legislation
}

\section{Paola Sobbrio}

Affiliated to Università Cattolica del Sacro Cuore, Piacenza, Italy

doi: 10.7358/rela-2013-001-sobb

psobbrio@hotmail.com

\begin{abstract}
Beginning with the Treaty of Amsterdam and then later with the Treaty of Lisbon (TFEU), Europe has more than once formally recognized nonbuman animals as sentient beings. This recognition spurred the creation of regulations that provide for the protection and promotion of animal welfare. However, this protection seems to contain many exceptions, particularly regarding the consideration from which these regulations stemmed: the recognition of animal sentience. In this paper, I argue that the regulations generated by this legislation, far from being aimed at improving the living conditions of nonbuman animals used by the buman animals, are actually put in place in order to obtain additional benefits for bumans. These benefits include, but are not limited to, the reduction of zoonotic diseases (in the case of nonbuman animals being used for breeding), and the improvement in predictability of animal models (in the case of nonbuman animals being used for experimental purposes). While the rhetoric of these laws seems to endorse the protection and welfare of animals as sentient beings, they actually allow for their enslavement and objectification. In the end, the credibility of Europe's acknowledgement of animal sentience is greatly bampered by the institutionalization of very cruel practices allowed by animal welfare regulations.
\end{abstract}

Keywords: Animal welfare, legislation, nonhuman animal, human animal, sentient beings, food, research, quality, strategy, European Union.

\section{INTRODUCTION}

The study of animal welfare is interdisciplinary. The concern for animal welfare (manifested in the creation of European standards on animal welfare) stems from concerns relating to animals being used in intensive farming. Animal Machines, written in 1964, was the first book to shed light upon the detention of animals on these farms (Harrison 1964). The book's

Relations - 1.I - June 2013

http://www.ledonline.it/Relations/ 
title - a Cartesian definition comparing nonhuman animals to machines - is a reaction to the treatment of animals not only on factory farms but also, more generally, in all cases in which human animals use nonhuman animals and do not consider them to be 'sentient beings'. In this essay, I will often use the terms 'human animal' and 'nonhuman animal' to emphasize that we all belong to the same animal kingdom (despite the way in which the former animal may treat the latter). In some instances, for the sake of brevity, I will use the more conventional terms: 'animal' and 'human'.

\section{Welfare of nONHUMAN ANimals in Europe}

In 1960, the Council of Europe promoted international agreements intended to protect animal welfare. In 1976, the European Convention for the protection of Animals kept for Farming Purposes was created, followed by the European Convention for the protection of Animals during International Transport in 1978. Since 1980, the European Union (EU) has issued a series of directives and regulations aimed at both horizontally and vertically protecting nonhuman animals used for a variety of purposes (food, fur, fun, pets, etc.). The EU has defined nonhuman animals as 'sentient beings' since the Treaty of Amsterdam, signed in 1997. However, defining animals as such appears to be a strategy aimed at protecting the human animal rather than the nonhuman animal.

Both the EU regulations on animal welfare and the numerous European legislative documents addressing this topic provide ample evidence that legislative considerations toward animal welfare are actually designed to assure human welfare - specifically in regard to the healthiness of human food and the protection of human health.

The close relationship between animal welfare, animal health, and animal productivity is also among the most common reasons for the promotion of animal welfare. For example, the FAO report explains that certain welfare-related measures are important for the prevention or reduction of animal injures and losses in order to improve meat quality, carcass quality, or production losses (Fraser et al. 2009, 31).

The above mentioned relationship has also been reaffirmed by the Welfare Quality® Project. Research conducted by this organization emphasizes the importance of animal welfare to European consumers, who readily correlate animal welfare with the quality of the food they eat. In an overview of the project's mission, the Welfare Quality ${ }^{\circledR}$ Project's website confirms that its interest in animal welfare is greatly motivated by the desire to preserve human welfare, stating that "The fact that improving the animal's welfare 
can positively affect product quality, pathology and disease resistance also has a direct bearing on food quality and safety" (Welfare Quality® 2009).

Even the European Food Safety Authority (EFSA) has dealt with animal welfare. Its pamphlet, Science Protecting Consumers from Field to Fork, highlights that the prevention of zoonotic diseases (about $75 \%$ of the new diseases that have affected humans since 2000 originated from animals or products of animal origin) can be achieved by adjusting the conditions and treatment of animals, in other words: through attention to animal welfare. For this reason, even the EFSA "assesses the safety of animal feed, which is important for the health of animals, the environment and for the safety of foods of animal origin" (EFSA 2012, 4).

More recently, the Communication from the Commission to the European Parliament, the Council and the European Economic and Social Committee on the European Union Strategy for the Protection and Welfare of Animals 2012-2015 mentions in its introduction that "Article 13 of the Treaty on the Functioning of the European Union recognizes animals as sentient beings and requires full regard be given to the welfare requirements of animals while formulating and enforcing some EU policies" (European Commission 2012, 2). The Strategy has even adopted the new slogan "Everyone is responsible". This slogan is indicative of the different multilevel initiatives that the Strategy has adopted. These initiatives include an improvement upon the training of animal caretakers and the creation of a new method of farm inspection that focuses on the animals themselves instead of the environment in which they live. Unfortunately, even in this document, there is evidence that the attention given to animal welfare is based in a desire to improve human welfare. Article 13 contains a contradiction in regard to the acknowledgement of animal sentience:

In formulating and implementing the Union's agriculture, fisheries, transport, internal market, research and technological development and space policies, the Union and the Member States shall, since animals are sentient beings, pay full regard to the welfare requirements of animals, while respecting the legislative or administrative provisions and customs of the Member States relating in particular to religious rites, cultural traditions and regional heritage. (Council of the European Union 2010)

This article asserts that nonhuman animals are living and sentient beings, but also explicitly allows for the disregard of their sentience in the case of religious rites, cultural traditions and regional heritage. The reason for this contradiction is greatly economic. In fact, the above mentioned communication also allows for the ignoring of animal sentience, not only for the aforementioned reasons, but also to support the livestock industry and to support both basic and pharmaceutical research. Systematic and institutionalized 
exploitation of nonhuman animals is promoted and supported by European policies and therefore directly undermines the statement that nonhuman animals are living and sentient beings able to experience feelings and emotions such as fear, hunger, cold, discomfort, pain, etc.

According to the Brambell Report (1965), the minimum conditions to ensure welfare for a nonhuman animal living in detention are represented by the five freedoms.

1. Freedom from Hunger and Thirst - by ready access to fresh water and a diet to maintain full health and vigour.

2. Freedom from Discomfort - by providing an appropriate environment including shelter and a comfortable resting area.

3. Freedom from Pain, Injury or Disease - by prevention or rapid diagnosis and treatment.

4. Freedom to Express Normal Behaviour - by providing sufficient space, proper facilities and company of the animal's own kind.

5. Freedom from Fear and Distress - by ensuring conditions and treatment which avoid mental suffering. (Farm Animal Welfare Committee 2011)

Considering only these five freedoms and not yet taking into account any other factors, how many nonhuman animals could we say enjoy and benefit from these five freedoms when they are subjected by humans to conditions of detention for the purpose of breeding, transportation or experimentation?

It is difficult to believe that nonhuman animals held in animal enclosures or forced to live on farms are free from fear and psychological suffering, or that they have the freedom to express the typical behavior of their species.

\section{WELFARE ASSESSMENT}

Welfare assessments contain physiological, behavioral, emotional, health related, and production related elements. There is no unequivocal definition of these assessments (Duncan 1993).

According to Broom, an individual's welfare is its state of being as it attempts to cope with its environment (1986). This definition claims that an individual's welfare can be scientifically measured and that it cannot be influenced by moral considerations (Broom 1991). Welfare can be measured according to well-defined indicators showing how the nonhuman animal copes with its environment and therefore whether or not it benefits from good or bad conditions. The World Organization for Animal Health (OIE) adopted this definition of animal welfare:

Animal welfare means how an animal is coping with the conditions in which it lives. An animal is in a good state of welfare if (as indicated by scientific evi-

Relations - 1.I - June 2013

http://www.ledonline.it/Relations/ 
dence) it is healthy, comfortable, well nourished, safe, able to express innate behavior, and if it is not suffering from unpleasant states such as pain, fear, and distress. Good animal welfare requires disease prevention and veterinary treatment, appropriate shelter, management, nutrition, humane handling and humane slaughter or killing. Animal welfare refers to the state of the animal; the treatment that an animal receives is covered by other terms such as animal care, animal husbandry, and humane treatment. (World Organisation for Animal Health [1968] 2012, 299)

Scientific assessments of welfare have also shown that a healthy animal will provide a healthy product - but can a sentient being be considered a product?

The Communication from the Commission to the European Parliament, the Council and the European Economic and Social Committee on the European Union Strategy for the Protection and Welfare of Animals 2012-2015 states that "livestock farming in the EU represents an annual value of 149 billion euros and the use of experimental animals is estimated to have an annual value of 930 million euros" (European Commission 2012, 3).

The European Union directly supports actions aimed at improving animal welfare through annual grants worth 70 million euros. It does so because the use of animals is economically important in terms of European market competitiveness.

As far back as 2002, the Commission has highlighted that a lack of synchronization in animal treatment regulations between third countries and Member States could create economic disadvantages for countries that adopt higher welfare standards (European Commission 2002).

This concern over competitive disadvantages has continued to hinder legislative progress for animal welfare. Even in recent years, no decisive steps have been taken towards a real improvement of animal welfare - even though it has been made clear that consumers prefer to consume a 'product' that comes from an animal reared in accordance with high welfare standards, as it results in a healthier 'product'.

Consumers are concerned about animal welfare. Especially after the BSE epidemic, consumers place great importance on the relationship between the quality of life of a farmed animal and the healthiness of the product it produces. Therefore, far from worrying about the conditions in which nonhuman animals live, consumers desire the best welfare standards for animals in order to ensure that the product that they consume will be both healthy and of good quality (Welfare Quality® 2009).

This approach to animal welfare can be confirmed by analyzing the horizontal legislation concerning farmed animals, i.e. general rules concerning the protection of farmed animals, irrespective of their species. 
The Council Directive 98/58/EC of 20 July 1998: Concerning the Protection of Animals Kept for Farming Purposes states that "there is therefore a need to establish common minimum standards for the protection of animals kept for farming purposes in order to ensure rational development of production and to facilitate the organization of the market in animals; whereas to that end it is appropriate to take account of animal welfare provisions already laid down in Community rules" (Council Directive 98/58/EC). It further states that "whereas a comparative examination of animal welfare provisions applicable in the Community and in certain non-member countries together with an appraisal thereof should be undertaken with a view to determining the nature of future Community initiatives aimed at eliminating distortions of competition" (Council Directive 98/58/EC).

This directive does not define welfare but it does indicate that there should be certain protective standards for animals. Article 3 provides that Member States must ensure that those who are responsible for animals do not cause them "unnecessary" pain, suffering, or injuries (Council Directive $98 / 58 / \mathrm{EC}$ ). But no subsequent legislative act specifies what is meant by the term 'unnecessary'.

\section{WELFARE AND SENTIENCE}

Unlike Broom, Duncan and Petherick claim that:

Animal welfare is dependent solely on the mental, psychological, and cognitive needs of the animals concerned. In general, if these mental needs are met, they will cover the physical needs. [...] We would argue that as long as the animal's mental state is protected (i.e. as long as the animal 'feels' all right) then its welfare will be all right. Now, of course, usually when an animal is ill, it will also feel ill, so that taking care of its mental state (i.e. how it feels) will automatically take care of its physical health. (Duncan and Petherick 1991, 5017-8)

This definition of welfare takes into account feelings and needs - not only physical needs but also, and above all, mental needs. By this definition, article 13 of TFEU (Council of the European Union 2010) continues to contradict itself. While it asserts that animals are sentient beings whose 'welfare requirements' must be taken into account by humans, it lacks any mention of their needs or feelings. The term 'requirements' is well suited to European legislation which does not take into account the needs, feelings, or emotions of nonhuman animals and that considers only the physical space and the environment in which animals are located. 
Underlying article 13 and all other animal welfare legislation is a reference to ethological assessments. In the Council Directive 98/58/EC of July 20,1998 , it is stated in the annex that "no animal shall be kept for farming purposes unless it can reasonably be expected, on the basis of its genotype or phenotype, that it can be kept without detrimental effect on its health or welfare" (Council Directive 98/58/EC). According to this part of the 1998 directive, no nonhuman animal could, therefore, be confined on a farm.

The Council Directive 2008/120/EC of December 18, 2008 sets minimum standards for the protection of pigs and is slightly more realistic: it explains that "a balance should be kept between the various aspects to be taken into consideration, as regarding welfare including health, economic and social considerations, and also environmental impact" (Council Directive 2008/120/EC). Similar considerations are also given to hens in the Council Directive 1999/74/EC of July 19, 1999, which sets minimum standards for the protection of laying hens (Council Directive 1999/74/EC). For the same reason, the aforementioned directive provides in annex I, chapter II that:

All procedures intended as an intervention carried out for other than therapeutic or diagnostic purposes or for the identification of the pigs in accordance with relevant legislation and resulting in damage to or the loss of a sensitive part of the body or the alteration of bone structure shall be prohibited with the following exceptions:

- a uniform reduction of corner teeth of piglets by grinding or clipping not later than the seventh day of life of the piglets leaving an intact smooth surface; boars' tusks may be reduced in length where necessary to prevent injuries to other animals or for safety reasons,

- docking of a part of the tail,

- castration of male pigs by other means than tearing of tissues,

- nose-ringing only when the animals are kept in outdoor husbandry systems and in compliance with national legislation. (Council Directive 2001/93/EC)

Listed above are the 'necessary' measures put in place to avoid any economic losses that could result from the frequent aggression displayed by pigs in reaction to conditions of overcrowding, characteristic of intensive farming.

\section{Welfare IN THE Directive 2010/63/EU}

OF THE EUROPEAN PARLIAMENT

AND THE COUNCIL ON THE PROTECTION OF ANIMALS

USED FOR SCIENTIFIC PURPOSES

On September 8, 2010, the European Parliament approved a long time coming revision of the text of Directive 86/609 (Council Directive 2010/63/ EU). The revision implemented improvements in the welfare conditions 
of farmed animals. It focused particularly on the promotion of alternative farming methods both because of progress that had been made in this area and also because experimentation on nonhuman animals had become increasingly ethically controversial.

Despite this revision, these advancements have been extensively disregarded by the directive - to such an extent that a European initiative has arisen, requesting their abrogation (STOP VIVISECTION 2012). On the European Commission website it is also written that the directive is characterized by its flexibility of use: it requires that member states reap results, but it allows those states ample freedom to choose the way in which they arrive at those results. The directive in question, however, is not the only directive which provides for the use of animals for scientific purposes; the REACH directive, which addresses the use of animals in toxicity testing of chemicals, also contains this allowance - Regulation (EC) no. 1907/2006 of the European Parliament and of the Council. It is estimated that 90,000 vertebrate animals will be used annually to introduce new chemicals in the environment $(68,000)$ (Rovida and Hartung 2009). The European Commission calculates that in ten years, between eight and 13 million animals may be used for research - this, of course, is in addition to the 12 million animals already allowed for in the Directive 63/2010 (European Commission 2010). Article 5 of the directive provides for the use of animals in research for:

(a) basic research;

(b) translational or applied research with any of the following aims:

(i) the avoidance, prevention, diagnosis or treatment of disease, illhealth or other abnormality or their effects in human beings, animals or plants;

(ii) the assessment, detection, regulation or modification of physiological conditions in human beings, animals or plants; or

(iii) the welfare of animals and the improvement of the production conditions for animals reared for agricultural purposes;

(c) for any of the aims in point (b) in the development, manufacture or testing of the quality, effectiveness and safety of drugs, foodstuffs and feedstuffs and other substances or products;

(d) protection of the natural environment in the interests of the health or welfare of human beings or animals;

(e) research aimed at preservation of the species;

(f) higher education, or training for the acquisition, maintenance or improvement of vocational skills;

(g) forensic inquiries. (Council Directive 2010/63/EU)

This almost all-inclusive list does not exclude the use of animals for educational purposes - an issue that, given the above assumptions, likely would have been prohibited by the new directive. 
The directive does not add to or improve upon the 3R Principle (Refine, Replace, and Reduce the number of animals used in experimentation), which had been introduced in the 1986 directive. These objectives had been abundantly emphasized in the previous directive, so much so that it led to the creation of ECVAM, a centre for the validation of alternative methods of animal testing (Council Directive 86/609/EEC).

The 2010 directive, contrary to what one might expect, does not prohibit the use of great apes but instead gives each Member State the power to prohibit specific uses as it sees fit. Examples of possible uses include: prophylaxis, prevention, diagnosis or treatment of disease, poor health condition or other abnormality as they effect humans, animals or plants; as part of the development, production or quality tests of effectiveness and safety of drugs, food, and other substances or products; research aimed at preservation of the species (Council Directive 2010/63/EU). In addition to this list, the directive also allows nonhuman primates to be used for basic research.

This directive, which constitutes the most afflictive legislation for nonhuman animals, does not neglect to address - at least rhetorically - animal welfare. The directive discusses the importance given to the socialization of animals and the enrichment of the spaces intended for animals (specifically in regard to cage size). The directive also made provisions for retrospective assessments of animal welfare projects in order to evaluate their usefulness, level of success in achieving predetermined objectives, transparency when publishing data; and to confirm the creation of an animal-welfare authority.

In this case, an animal-welfare authority, provided for by article 26 , would consist of the person or persons responsible for the welfare and care of the animals and, in certain cases, of one scientific member. A veterinarian appointed by an expert described in article 25 would also contribute to the animal-welfare authority (Council Directive 2010/63/EU).

The directive does not clearly specify who these figures would be, who would appoint them, or by whom they would be paid. Furthermore, under this legislation, it is unclear whether or not it would still be possible for the owner of the animal establishment to choose and reimburse the veterinarian responsible for verifying animal welfare.

The terms, 'ethical treatment of animals', 'humane treatment', and 'animal welfare' are used only rhetorically in this directive. Annex VIII, entitled Severity Classifications, divides animal procedures into three categories based on severity. The first one is mild: "Procedures on animals as a result of which the animals are likely to experience short-term mild pain, suffering or distress, as well as procedures with no significant impairment of the well-being or general condition of the animals" (Council Directive 
2010/63/EU). The second is moderate, "Procedures on animals as a result of which the animals are likely to experience short-term moderate pain, suffering or distress, or long-lasting mild pain, suffering or distress as well as procedures that are likely to cause moderate impairment of the wellbeing or general condition of the animals" (Council Directive 2010/63/ EU). The last one is severe, "Procedures on animals as a result of which the animals are likely to experience severe pain, suffering or distress, or long-lasting moderate pain, suffering or distress as well as procedures, that are likely to cause severe impairment of the well-being or general condition of the animals" (Council Directive 2010/63/EU).

In section III on annex VIII, examples of 'mild' procedures include, among others:

(g) induction of tumors, or spontaneous tumors, that cause no detectable clinical adverse effects (e.g. small, subcutaneous, non-invasive nodules);

(h) breeding of genetically altered animals, which is expected to result in a phenotype with mild effects;

(i) feeding of modified diets, that do not meet all of the animals' nutritional needs and are expected to cause mild clinical abnormality within the time-scale of the study;

(j) short-term $(<24 \mathrm{~h})$ restraint in metabolic cages;

(k) studies involving short-term deprivation of social partners, short-term solitary caging of adult rats or mice of sociable strains. (Council Directive 2010/63/EU)

Examples of 'moderate' procedures found in the same part of the directive include:

(c) surgery under general anesthesia and appropriate analgesia, associated with post surgical pain, suffering or impairment of general condition; examples include: thoracotomy, craniotomy, laparotomy, orchidectomy, lymphadenectomy, thyroidectomy, orthopedic surgery with effective stabilization and wound management, organ transplantation with effective management of rejection, surgical implantation of catheters, or biomedical devices (e.g. telemetry transmitters, minipumps etc.);

(d) models of induction of tumors, or spontaneous tumors, that are expected to cause moderate pain or distress or moderate interference with normal behavior;

(e) irradiation or chemotherapy with a sublethal dose, or with an otherwise lethal dose but with reconstitution of the immune system; adverse effects would be expected to be mild or moderate and would be shortlived ( $<5$ days);

(f) breeding of genetically altered animals which are expected to result in a phenotype with moderate effects;

(g) creation of genetically altered animals through surgical procedures; 
(h) use of metabolic cages involving moderate restriction of movement over a prolonged period (up to 5 days);

(i) studies with modified diets that do not meet all of the animals' nutritional needs and are expected to cause moderate clinical abnormality within the time-scale of the study;

(j) withdrawal of food for 48 hours in adult rats;

(k) evoking escape and avoidance reactions where the animal is unable to escape or avoid the stimulus, and are expected to result in moderate distress. (Council Directive 2010/63/EU)

Finally, despite the rhetorical consideration given to "animals welfare" and "ethological needs" of animals, section III of the directive indicates the following as examples of severe procedures:

(a) toxicity testing where death is the end-point, or fatalities are to be expected and severe pathophysiological states are induced; for example, single dose acute toxicity testing (see OECD testing guidelines);

(b) testing of device where failure may cause severe pain, distress or death of the animal (e.g. cardiac assist devices);

(c) vaccine potency testing characterized by persistent impairment of the animal's condition, progressive disease leading to death, associated with long-lasting moderate pain, distress or suffering;

(d) irradiation or chemotherapy with a lethal dose without reconstitution of the immune system, or reconstitution with production of graft versus host disease;

(e) models with induction of tumors, or with spontaneous tumors, that are expected to cause progressive lethal disease associated with longlasting moderate pain, distress or suffering, for example tumors causing cachexia, invasive bone tumors, tumors resulting in metastatic spread, and tumors that are allowed to ulcerate;

(f) surgical and other interventions in animals under general anesthesia which are expected to result in severe or persistent moderate postoperative pain, suffering or distress or severe and persistent impairment of the general condition of the animals; production of unstable fractures, thoracotomy without adequate analgesia, or trauma to produce multiple organ failure;

(g) organ transplantation where organ rejection is likely to lead to severe distress or impairment of the general condition of the animals (e.g. xenotransplantation);

(h) breeding animals with genetic disorders that are expected to experience severe and persistent impairment of general condition, for example Huntington's disease, muscular dystrophy, chronic relapsing neuritis models;

(i) use of metabolic cages involving severe restriction of movement over a prolonged period;

(j) inescapable electric shock (e.g. to produce learned helplessness);

Relations - 1.I - June 2013

http://www.ledonline.it/Relations/ 
(k) complete isolation for prolonged periods of social species e.g. dogs and non-human primates;

(1) immobilization stress to induce gastric ulcers or cardiac failure in rats;

(m) forced swim or exercise tests with exhaustion as the end-point. (Council Directive 2010/63/EU)

\section{ConClusion}

In European legislation, the term 'animal welfare' has become a buzzword used to draw a connection between the improvement in living conditions for nonhuman animals and the improvement in that of human welfare. After examining legislative rules and documents, it is clear that, while nonhuman animals are formally considered sentient beings, they are treated as insentient and considered to be objects of consumption, commodities, products, and means of production. The nonhuman animal, whether it is intended to produce meat, milk, eggs, medicine, or a new therapy, is a means by which Europe bases its economic growth and its ability to compete in the world market. Every year, billions of nonhuman animals (fish included) are bred, housed, butchered and slaughtered to satisfy the European economic market. Faced with this axiomatic evidence, it can be concluded that the welfare considerations on which animal regulations are based - not to mention, the (obvious) assertion that nonhuman animals are sentient beings constitutes only a rhetorical narrative hiding one single concern: the desire to safeguard the welfare of other animals. Human animals.

\section{REFERENCES}

Brambell, Rogers F.W. (Chairman). 1965. Report of the Technical Committee to Enquire into the Welfare of Animals Kept under Intensive Livestock Systems. London: Her Majesty's Stationery Office.

Broom, Donald M. 1986. "Indicators of Poor Welfare”. British Veterinary Journal 142 (6): 524-6. doi: 10.1016/0007-1935(86)90109-0.

_ 1991. "Animal Welfare: Concepts and Measurement". Journal of Animal Science 69 (10): 4167-75.

Council Directive. 1986. "Approximation of Laws, Regulations and Administrative Provisions of the Member States Regarding the Protection of Animals Used for Experimental and Other Scientific Purposes. Council Directive 86/609/ EEC of 24 November 1986". Official Journal of the European Union L 358 (18/12/1986): 1-28.

1998. "Concerning the Protection of Animals Kept for Farming Purposes. Council Directive 98/58/EC of 20 July 1998”. Official Journal of the European Communities L 221 (08/08/1998): 23-7. 
1999. "Laying down Minimum Standards for the Protection of Laying Hens". Official Journal of the European Communities L 203 (03/08/1999): 53-7.

2001. “Amending Directive 91/630/EEC Laying down Minimum Standards for the Protection of Pigs. Council Directive 2001/93/EC of 9 November 2001". Official Journal of the European Communities L 316 (01/12/2001):36-8. 2009. "Laying down Minimum Standards for the Protection of Pigs. Council Directive 2008/120/EC”. Official Journal of the European Union L 47 (18/02/2009): 5-13.

2010. "On the Protection of Animals Used for Scientific Purposes. Council Directive 2010/63/EU of 22 September 2010". Official Journal of the European Union L 276 (20/10/2010): 33-79.

Council of the European Union. 2010. "Consolidated Versions of the Treaty on European Union and the Treaty on the Functioning of the European Union”. Official Journal of the European Union C 83 (30/03/2010).

Duncan, Ian J.H. 1993. "Welfare Is to Do with What Animals Feel". Journal of Agricultural and Environmental Ethics 6, Supplement 2: 8-14.

Duncan, Ian J.H., and Carol J. Petherick. 1991. "The Implications of Cognitive Processes for Animal Welfare”. Journal of Animal Science 69 (12): 5017-22.

EFSA. 2012. Science Protecting Consumers from Field to Fork. Accessed December 6, 2012. http://www.efsa.europa.eu/en/corporate/doc/efsacorporatebrochure.pdf.

European Commission. 2010. "Sixth Report on the Statistics on the Number of Animals Used for Experimental and Other Scientific Purposes in the Member States of the European Union SEC(2010) 1107". Official Website of the European Union. Accessed December 6, 2012. http://eur-lex.europa.eu/ LexUriServ/LexUriServ.do?uri=COM:2010:0511:REV1:EN:PDF.

2012. "Communication from the Commission to the Council and the European Parliament on Animal Welfare Legislation on Farmed Animals in Third Countries and the Implications for the EU". Official Website of the European Union. Accessed December 6, 2012. http://ec.europa.eu/food/animal/ welfare/references/2002_0626_en.pdf.

2012. "Communication from the Commission to the European Parliament, the Council and the European Economic and Social Committee on the European Union Strategy for the Protection and Welfare of Animals 2012-2015”. Official Website of the European Union. Accessed December 6, 2012. http://ec.europa. eu/food/animal/welfare/actionplan/docs/aw_strategy_19012012_en.pdf.

European Parliament, and Council. 2006. "Concerning the Registration, Evaluation, Authorisation and Restriction of Chemicals (REACH), Establishing a European Chemicals Agency, Amending Directive 1999/45/EC and Repealing Council Regulation (EEC) no. 793/93 and Commission Regulation (EC) no. 1488/94 as well as Council Directive 76/769/EEC and Commission Directives 91/155/EEC, 93/67/EEC, 93/105/EC and 2000/21/EC. Regulation (EC) no. 1907/2006 of the European Parliament and Council of 18 December 2006”. Official Journal of the European Union L 396 (20/12/2006).

Farm Animal Welfare Committee. 2011. "Five Freedoms”. FAWC. Accessed December 6, 2012. http://www.defra.gov.uk/fawc/about/five-freedoms. 
Fraser, David, et al. 2009. Capacity Building to Implement Good Animal Welfare Practices Report of the Fao Expert Meeting - Fao Headquarters (Rome) 30 September - 3 October 2008. Rome: Food and Agriculture Organization of the United Nations.

Harrison, Ruth. 1964. Animal Machines. London: Stuart.

Rovida, Costanza, and Thomas Hartung. 2009. "Re-evaluation of Animal Numbers and Costs for In Vivo Tests to Accomplish REACH Legislation Requirements for Chemicals - A Report by the Transatlantic Think Tank for Toxicology (t4)". Altex 26 (3): 187-208.

STOP VIVISECTION. 2012. What is STOP VIVISECTION. Accessed December 6, 2012. http://www.stopvivisection.eu/en/content/what-stop-vivisection.

Welfare Quality®. 2009. Project Overview. Accessed December 6, 2012. http://www. welfarequality.net/everyone/26536/5/0/22.

World Organisation for Animal Health. (1968) 2012. Terrestrial Animal Health Code. Volume I. Paris: Office International Epizooties. 